\title{
Responses to direct and indirect selection on aerial dispersal behaviour in Tetranychus urticae
}

\author{
JIANBO LI \& DAVID C. MARGOLIES* \\ Department of Entomology, Kansas State University, Manhattan, KS 66506-4004, U.S.A.
}

\begin{abstract}
Dispersal within and between hosts is an important element of arthropod life histories. This study was designed to assess adaptability of traits related to dispersal and colonization in the twospotted spider mite, Tetranychus urticae. Defining the flexibility of mite dispersal and life-history is necessary to understand the response of mites to changes in the spatial and temporal structure of their environment. We found significant direct response to bidirectional selection on aerial dispersal behaviour after eight and five generations of selection. The realized heritability estimated from these lines $\left(h^{2}=0.28\right)$ was in close agreement with that estimated in a previous sib-analysis on the base population. As predicted from the sib-analysis, there were no correlated responses in fecundity or sex ratio. Crosses between selected lines indicated that the dispersal behaviour was under weak maternal influence and that non-dispersal may be a slightly dominant trait. Mite sensitivity or resistance to starvation or desiccation, the major environmental cues triggering their behaviour, changed in response to selection. Results suggest that variation in aerial dispersal behaviour is largely attributed to different sensitivity or resistance to environmental stress and that genetic variation in this behaviour may be maintained by selection for dispersal when food resources become depleted and against when food is abundant. The dispersal behaviour itself, although not correlated with reproductive traits, may increase mite fitness in temporally and spatially fluctuating environments.
\end{abstract}

Keywords: aerial dispersal, environmental variation, life-history, selection, Tetranychus urticae

\section{Introduction}

Dispersal is the process whereby an individual abandons an actually or potentially deteriorating host or habitat. Successful dispersal also involves colonizing a new host. This process is an essential feature of arthropod survival in spatially and temporally varying environments (Southwood, 1962; Safriel \& Ritte, 1980; Parsons, 1983). The evolution of dispersal in varying environments depends in large part on the genetic architecture of an arthropod population (Dingle, 1984). The important concerns in terms of varying environments are the genetic basis of dispersal, genetic organization of traits related to dispersal and the intensity of selection imposed by the environment. These issues determine the rate and direction in which

${ }^{*}$ Correspondence. dispersal traits may evolve (Dingle et al., 1982; Lande, 1982).

The twospotted spider mite, Tetranychus urticae Koch (Acari: Tetranychidae), is a highly polyphagous arthropod among whose hosts are many crops (Jeppson et al., 1975). Crop systems in which the twospotted mite is commonly found are subjected to frequent natural and imposed disturbances, such as host senescence and harvesting, that create emphemeral environments for the mite. However, agroecosystems also provide mites with a series of temporally and spatially available hosts that they can exploit. Therefore, dispersal and colonization of new hosts are significant elements in the biology of the twospotted spider mite, contributing both to persistence of the species in natural and artificial (e.g. greenhouse, field crop) ecosystems (Kennedy \& Margolies, 1985a,b). Mites can achieve long distance dispersal as 
aerial plankton on wind currents (Brandenburg \& Kennedy, 1982; Hoy et al., 1984). Aerial dispersal in tetranychid mites does not occur primarily by chance but is the result of an active behaviour that enhances the probability of mites being carried aloft from plant surfaces (Smitley \& Kennedy, 1985; Margolies, 1987). Mites engage in this behaviour in immediate response to desiccation or starvation (Suski \& Naegele, 1963; Smitley \& Kennedy, 1985; Margolies \& Kennedy, 1988), both of which are most likely to occur as host quality declines. Aerial dispersal, therefore, occurs as a response to host or habitat deterioration. This allows mites to find new and previously uninfested hosts and habitats.

There is significant intraspecific variation within mite populations in the propensity for individuals to exhibit the aerial dispersal behaviour under proscribed experimental conditions (Smitley \& Kennedy, 1985). Our previous work based on a sib-analysis ( $\mathrm{Li} \&$ Margolies, 1993b) demonstrated that variation in the propensity to initiate aerial dispersal behaviour was under genetic control; additive genetic variation in aerial dispersal behaviour accounted for 22 per cent of the total variation $\left(h^{2}=0.22\right)$. However, a simple knowledge of heritability may not predict the actual response to selection. Duration of the selection response, the phenotypic limit at which there is no further selection response, and the symmetry of that response depend on the genetic architecture. These properties of the selection response were examined in this study by imposing bidirectional selection on aerial dispersal behaviour.

The objectives of our present study were threefold. Firstly, we tested whether the response of the twospotted spider mite to direct selection on aerial dispersal behaviour was as predicted in the previous sib-analysis. Several other traits in spider mites have been found to be highly responsive to directional selection, including diapause (Helle, 1985), sex ratio (Mitchell, 1972) and the ability to adapt to new host plants (Gould, 1979; Fry, 1989). We were particularly interested in the rate of and limits to the selection response. Selection limits may be imposed on a population either because of constraints by correlated traits or because all the alleles affecting the trait are either fixed or lost, neither of which is obvious from estimates of genetic variance and covariance through a sib-analysis alone. It is also possible that artificial selection on dispersal is opposed by natural selection on dispersal or some correlated traits. We examined this possibility by relaxing artificial selection on dispersal to see if natural selection acting alone would reverse the changes obtained by direct selection on the aerial dispersal trait.
Secondly, we assessed the existence of phenotypic correlations between the dispersal behaviour, fecundity and sex ratio. The ability and propensity to disperse may be genetically correlated with other traits (Palmer \& Dingle, 1986; Dingle et al., 1988; Gu \& Danthanarayana, 1992). Such correlations might facilitate or constrain adaptation to variable environments (Lande, 1982; Rose, 1982; Endler, 1986; Clark, 1987; Travis et al., 1987; Dingle, 1991). Although we did not see genetic or phenotypic correlations between aerial dispersal behaviour and traits associated with successful colonization (i.e. fecundity and sex ratio) in our sib-analysis, lack of evidence may have been due to the large standard errors that are usually associated with sib-analyses (Falconer, 1981; Rose \& Charlesworth, 1981a) rather than a real lack of correlations. A selection study of longer duration might reveal weak correlations that were not apparent by sibanalysis (Rose \& Charlesworth, 1981b).

Finally, we examined possible underlying mechanisms that influence dispersal behaviour. Starvation and desiccation condition the initiation of aerial dispersal behaviour in spider mites (Smitley \& Kennedy, 1985; Margolies \& Kennedy, 1988; Li \& Margolies, 1993a). If variation in sensitivity to these underlying characters contributes to variation in dispersal, environmental variance of dispersal would be increased, heritability decreased and the response to selection reduced (Riska, 1989; Houle, 1991; Price \& Schluter, 1991). Therefore, we also examined the possibility that variation in sensitivity to these factors is the basis for variation in the trait and that selection causes changes in mite sensitivity. Furthermore, we made crosses between selected lines to assess the role of non-additive effects, particularly maternal inheritance and dominance, on the selection response.

\section{Materials and methods}

\section{Aerial dispersal}

When food resources become depleted female mites may initiate an aerial dispersal behaviour that enables them to become airborne (Hoy et al., 1984; Smitley \& Kennedy, 1985). They can land on plants in surrounding areas or at a distance of several kilometres (Brandenburg \& Kennedy, 1982). Although mites in all life stages, except adult males, can display aerial dispersal behaviour when food is denied and both light and wind are present (Smitley \& Kennedy, 1985), young adult females (1-2 days old) are the predominant dispersers (Li \& Margolies, 1993a). Therefore, only 1-2day-old adult females were tested for dispersal behaviour. Experiments were always started with even- 
age cohorts of pre-reproductive female mites. These females were easy to find in a population because of the mating behaviour of the mites. About 1 day prior to adult emergence, both male and female mites enter an immobile stage called quiescent deutonymph. Female quiescent deutonymphs were easy to identify because they were usually guarded by adult males waiting to mate with them. Because virgin females display aerial dispersal behaviour at a much lower frequency than mated ones (Collins \& Margolies, 1991), guarding males were collected as we collected the quiescent female deutonymphs and were placed together so mating would take place when adult females emerged. All collected mites were kept on detached lima bean leaves, with abaxial surfaces up, pressed onto wet cotton in petri dishes. Tests in each generation were conducted on the two days following deutonymph collection.

In the presence of both light and wind, mites disposed to disperse will orient away from the light and raise their forebodies and forelegs; we defined this posture as the aerial dispersal (initiation) behaviour. Therefore, all tests were run under conditions of wind and light necessary to elicit this behaviour as described by Li \& Margolies (1993b). Test arenas were made from inverted petri dishes painted flat black. A small amount of tanglefoot (The Tanglefoot Co., Grand Rapids, Michigan) was applied to the upper edge of each arena to confine mites on top during a test. In the selection study, five test arenas with 40 mites per arena were used in a test, two for each selected line and one for the unselected control. The arenas were placed in a row at a $90^{\circ}$ angle to the direction of the wind and arena positions were changed once every $30 \mathrm{~min}$ during a test to avoid any bias introduced by arena position. We transferred mites from leaves in petri dishes onto each arena and tested them immediately. We subjected mites to test conditions continuously for $3 \mathrm{~h}$; more than half of the mites from the base population showed the behaviour within that time (J. Li \& D. C. Margolies, unpublished data). Mites that showed the behaviour were removed from the arena to a leaf in a petri dish according to their latency, i.e. the number of minutes from the beginning of the test to the onset of the behaviour. At the end of the test we recorded the total number of mites that displayed the behaviour. Significant day-to-day variation occurred in the incidence of the behaviour owing to uncontrolled meteorological conditions such as barometric pressure (J. Li \& D. C. Margolies, unpublished data). Because tests were conducted over 2 days, mites from the three lines were tested together each day so that comparisons could be made between lines using statistical methods for related samples. Five tests were conducted in each generation.

\section{Direct selection}

The laboratory population from which experimental lines were selected was started with twospotted spider mites collected from vetch plants near Jackson Springs, North Carolina. The base population was maintained on lima bean plants, Phaseolus lunatus L., in our laboratory for 18 months, or about 30 generations, prior to the experiments. Conditions were 16:8 LD photoperiod, $28-29^{\circ} \mathrm{C}$ temperature and $40-50$ per cent relative humidity for the base population and the selected lines. However, maintenance of the base population differed from that of the experimental lines in a manner that became important to our results and, therefore, requires a detailed description. Lima bean plants on which we maintained the base population were grown in a greenhouse in $40 \times 60 \mathrm{~cm}$ flats. We gave the population fresh food by placing a flat of uninfested plants adjacent to a flat of infested plants inside a large screened cage. As the mites fed on and destroyed one flat of plants they would move to the adjacent fresh plants. The important point here was that mites in the base population experienced variation in food quality and had to disperse between flats.

We maintained the experimental lines described below in a rearing room separate from the laboratory in which we kept the base population and from the room in which we conducted tests. These lines were isolated from each other within the rearing room in screened culturing cages similar to those described in Dennehy \& Granett (1984). Each cage was placed on an 'island' created by inverting a clay pot in the centre of a $1 \times 1 \mathrm{~m}$ pan filled with water to prevent mites moving between cultures. Pots of uninfested beans were placed between cages to detect mite dispersal between, and possible contamination of, experimental lines. We kept the lines in these cages on greenhousegrown bean plants in $21 \mathrm{~cm}$ diameter pots. A single pot of beans was sufficient to raise one generation of mites without much damage to the plant. Therefore, mites in the experimental lines experienced a consistently good quality environment.

Two replicates of selection were run; in each, three lines were selected from the laboratory population on the basis of aerial dispersal behaviour of individual mites: disperser, non-disperser and an unselected population. The unselected population was maintained as a control to separate genetic changes from environmental trends over time. To start the lines, 500 quiescent female deutonymphs were collected with their guarding males from the base population on moderately infested bean leaves. On the day following deutonymph collection, 100 newly emerged and presumably mated adult females were collected from the 500 to start the unselected control. The remaining 400 
female mites were tested for aerial dispersal as described below. The first 100 mites that showed the behaviour were used to start the disperser line whereas 100 mites that did not show the behaviour during the test were used to start the non-disperser line.

Bidirectional selection on aerial dispersal behaviour was imposed for eight generations in the first replicate and five in the second; we lost one line in the second replicate at that point in the experiment. One generation occurs every $2-3$ weeks at $25^{\circ} \mathrm{C}$. Because there are six to eight generations per year in the field, we thought five to eight generations should be sufficient to detect an ecologically significant response. For each generation after the first, 400 quiescent female deutonymphs from the disperser line, 400 from the non-disperser line and 200 from the unselected control were collected and tested for the dispersal behaviour on the day following the collection. The first 100 mites from the disperser line that displayed the behaviour and $\mathbf{1 0 0}$ from the non-disperser line that did not show the behaviour were used to start the next generation of each respective line. An additional 100 females were collected from the unselected control to start the next generation of that line.

Although both the proportion of mites displaying aerial dispersal behaviour and the latency of individual display were recorded, the behaviour was analysed as a threshold trait because in each generation a large number of mites did not show the behaviour and, therefore, latency data were not available for all mites used. Realized heritability of the proportion of mites showing the behaviour in both selected lines and their divergence were estimated following Falconer (1981).

Generation mean, $z$, and selection differential, $i$, were measured in units of standard deviation from the threshold of the behaviour. $z$ and $i$ were calculated from a standard normal density curve using a computer program for numerical integration based on the known proportion of dispersers in a generation. For a given proportion, $p_{i}$, of responders (i.e. dispersers in the disperser line or non-dispersers in the non-disperser line), $z$ was evaluated approximately from

$p_{i}=0.5 \pm \int_{O}^{z}\left((2 \pi)^{1 / 2}\right)^{-1} \exp \left(-z^{2} / 2\right) d z$.

The value of $z$ so estimated was positive $(+)$ when $p_{i}$ was smaller than 0.5 and negative $(-)$ when $p_{i}$ was larger than 0.5 . For graphic presentation of the realized heritability the sign was reversed before analysis; this did not affect the estimation of heritability or its standard error. The value of $i$ is $\exp \left(-z^{2} / 2\right)\left((2 \pi)^{1 / 2} p_{i}\right)^{-1}$. Generation mean, $z$, in the unselected control also was estimated so that any environmental effect on the two selected lines could be adjusted by the control means (Hill, 1972).

To estimate realized heritability in selected lines, generation means were adjusted by taking the difference between each selected line mean and that of the unselected control. Adjusted means were regressed on cumulative selection differentials of the appropriate selected line. To estimate realized heritability of the divergence of the two lines, absolute values of $z$ and $i$ in each generation from both selected lines were summed for new generation means and selection differentials. Realized heritability was then estimated as the slope of generation means regressed on cumulative selection differentials (Hill, 1972). This estimate was unbiased but its variance was an underestimate of the true variance because a selected line is only a finite sample of the base population and genetic drift becomes influential in later generations of selection (Hill, 1972, 1980). Therefore, the variance of heritability was estimated empirically from replicate lines. Dispersal behaviour is greatly influenced by host quality (Li \& Margolies, 1993a) and meteorological factors associated with tests (J. Li \& D. C. Margolies, unpublished data). Because of this, between-generation variance could be greater than sampling error so that the standard error of the regression line, which may be conservative in this case, also was used for heritability.

\section{Correlated responses to selection}

Spider mites reproduce by arrhenotoky; i.e. unfertilized eggs give rise to haploid male offspring, whereas fertilized eggs produce diploid females. Mated females produce both fertilized and unfertilized eggs (Helle, 1967); however, more daughters than sons (usually $3: 1$ ) are produced under normal environmental conditions (Krainacker \& Carey, 1990). Each mated female may produce 50 or more female offspring, which contributes to a high rate of population increase (Jeppson et al., 1975).

To estimate fecundity and sex ratio, 15 mites from each line were saved and reared individually on bean plants grown in bottles $\left(50-60 \mathrm{~cm}^{3}\right)$. Two holes $(1 \mathrm{~cm}$ diameter) were made in each bottle lid; one hole was used for inserting a pipette tip that supported a bean stem and the other for adding water. A greenhousegrown lima bean plant at the two-leaf stage was cut with a stem $8-10 \mathrm{~cm}$ long and inserted through the tip into the bottle. Roots grew out from the stem in a few days and the plants lived throughout an experiment.

One female mite quiescent deutonymph and a guarding male were placed on each leaf. A mite fed and laid eggs for 6 days before we removed her; this was sufficient time for a female to lay about 75 per cent of 
her eggs (Krainacker \& Carey, 1990). The offspring fed for another 8 days after the mother was removed, by which time eggs laid on day 6 had emerged as adults. We counted offspring and recorded their sex when they reached maturity. If all offspring were male we concluded that the original mating was not successful and dropped that datum from the analysis.

Fecundity and offspring sex ratio were measured in the base population and subsequent even number generations for each of the three lines in the first replicate of selection. The same measurements were made in the base population and at the end of selection in the second replicate. In addition, phenotypic correlations between aerial dispersal behaviour, fecundity and sex ratio were estimated.

Line differences in fecundity and sex ratio were compared in the generations where the traits were measured using the SAS GLM procedure (SAS Institute Inc., 1990). Generation means were regressed on generation numbers and slopes of the regression lines were estimated to examine the responses of these traits to selection. Fecundity was subjected to square-root and sex ratio to arcsine-square-root transformations to normalize the data for analysis (Sokal \& Rohlf, 1981).

\section{Crosses between selected lines}

At the end of selection, reciprocal crosses were made between disperser and non-disperser lines to estimate possible dominance or maternal effect on aerial dispersal behaviour. The two parental lines were used as controls. Crosses between populations or lines can be made by isolating female teliochrysali from one populaton with adult males from the second and vice versa. For each cross, 50 quiescent female deutonymphs were collected and placed on bean leaves along with about 50 adult males from either the same or the other selected line. Mites were reared on bean plants in the same manner as described in the selection study. When a sufficient number of offspring had matured, 200 female deutonymphs and their guarding males were collected from each cross and five tests with all crosses included were conducted in the same manner as described in the selection study. We also examined fecundity and sex ratio in the crosses from the first replicate. Ten pairs of newly emerged virgin females and adult males were matched appropriately for the four crosses. The mites were reared individually on bean plants grown in bottles, their offspring were counted and sex was determined in the same manner as described in the previous section.

Fecundity and sex ratio were compared between crosses using the SAS ANOva procedure. Prior to analysis, the data were transformed into the same scales as described in the previous section. The proportion of mites displaying aerial dispersal behaviour was analysed with a nonparametric method, Friedman two-way analysis of variance by ranks (Daniel, 1990), treating cross as a main factor and test date as a block factor because of significant among-test variation ( $\mathrm{Li} \&$ Margolies, 1993a). The Wilcoxon matched-pairs signed-ranks test was used to locate differences and test for significance between crosses.

\section{Relaxation of selection}

Selection was relaxed at the end of the eighth generation in the first replicate of selection. Response of the dispersal behaviour to relaxation in the disperser line was measured for seven generations. To start the relaxation, 100 female deutonymphs and their guarding males were collected from the eighth and each subsequent generation and the mites were reared on bean plants in the same manner as described in the selection study. We collected and tested 200 female mites for dispersal behaviour in each subsequent generation when a sufficient number became adults.

\section{Indirect selection}

During the first replicate of selection, the incidence of dispersal in the unselected control declined significantly whereas it did not change in the disperser lines. This suggested that dispersers were at a selective disadvantage under experimental conditions unless we imposed direct selection for them. Noting the difference in population maintenance procedures between the base population and experimental lines, we hypothesized that a continuous and abundant supply of a high quality food resource would select against dispersal whereas a variable environment could select for dispersal. To test this we discontinued direct selection on one group of mites from each of the selected lines but subjected them to a fluctuating environment created by varying food quality. We accomplished this by keeping alternate generations on fresh bean leaves or older leaves that showed previous feeding damage.

To start these lines, 100 female deutonymphs and their guarding males were collected from each selected line at the eighth generation. The offspring of these foundresses experienced good quality leaves but feeding damage decreased the food quality which the next (second) generation experienced. When the plants were about completely depleted by mite feeding, 1001 -dayold female mites were collected to start the next (third) generation on fresh plants. This cycle was repeated for nine generations. At the end of each third generation, when the plants were still in good condition, 120 
1-day-old female mites were collected and tested from each line; three such tests were done in the course of the experiment (i.e. third, sixth and ninth generations).

The mean proportions of mites displaying aerial dispersal behaviour from both selected and relaxed lines were regressed on generation numbers. Slopes of these regressions were compared as changes occurred during the course of selection.

\section{Food deprivation and dispersal}

At the end of selection, mites from both disperser and non-disperser lines were collected and starved for either $90 \mathrm{~min}$ or $8 \mathrm{~h}$, after which they were tested for the dispersal behaviour in the same manner as described in the selection study. In each starvation experiment we used about 600 mites from each line in five tests.

The mean proportion and latency of aerial dispersal behaviour were compared among the three selected lines in generations 0,4 and 8 , and between the two experiments involving starvation using nonparametric methods: the Kruskal-Wallis one-way nonparametric ANOVA and the Mann-Whitney $U$-test, respectively. Individual latency in the selected lines and the starvation experiments was first transformed into squareroot scale and then its frequency distributions were plotted at intervals of 1 on the transformed scale.

\section{Results}

\section{Direct response to selection}

Aerial dispersal behaviour, measured as the proportion of mites displaying it, responded to selection in both replicates (Fig. 1). Heritability estimates based on regression of the responses on cumulative selection differentials were significantly larger than zero with one exception and that exception was nearly significant (Fig. 2). The estimates of heritability (average $=0.28$ )

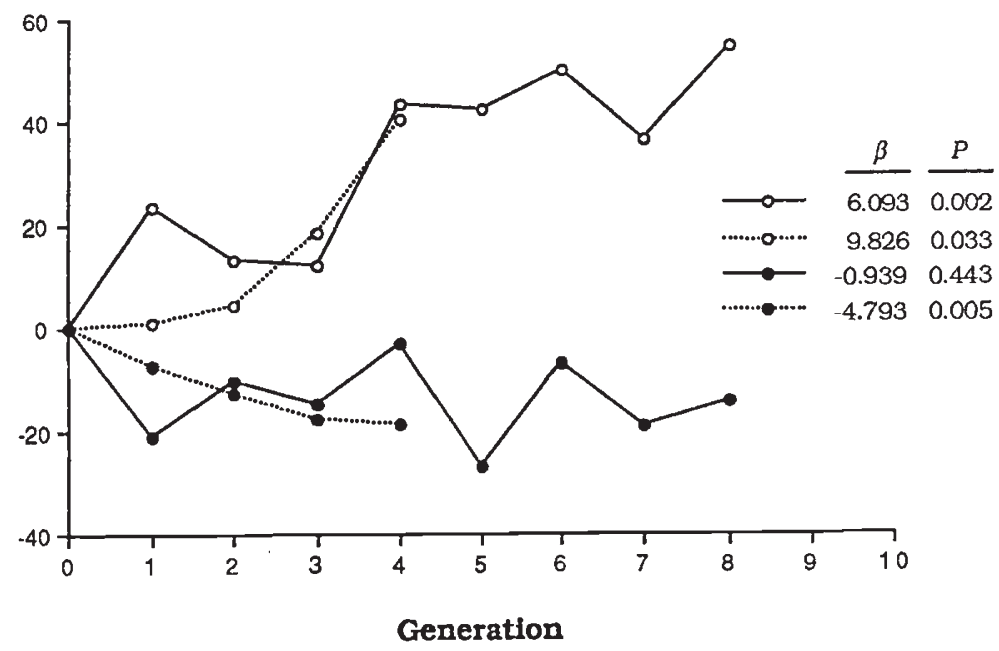

Fig. 1 Mean responses of aerial dispersal behaviour measured as the proportion of mites displaying the behaviour in selected lines from both replicates after being adjusted by unselected control. The proportion of mites showing the behaviour in the initial generation was 67.2 per cent in the first replicate and 59.7 per cent in the second. Open circles represent the disperser lines and closed circles represent the non-disperser lines; solid lines are for the first replicate and broken lines, the second. $\beta$ is the slope of the response, and $P$ is the significance of the deviation of the slope from 0 .

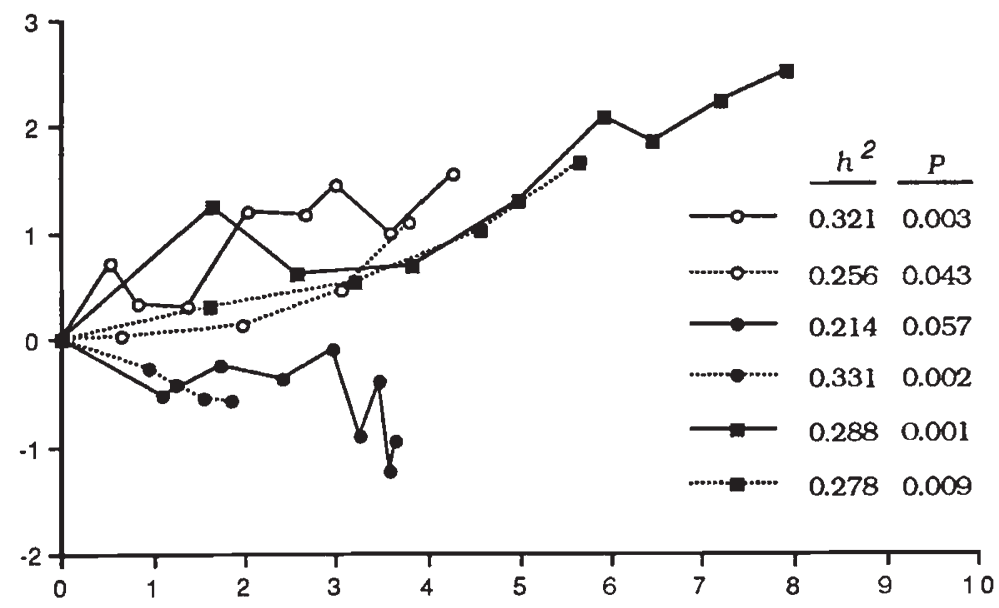

Cumulative selection differentials (i)

Fig. 2 Mean responses, in units of standard deviation, regressed on cumulative selection differentials. Realized heritability, $h^{2}$, is estimated as the slope of the regression. Closed squares represent the difference between selected lines. Other symbols as in Fig. 1. 
agreed well between lines and experiments. We did not find any mites on indicator plants in the rearing room and therefore concluded there was no accidental movement or gene flow between selected lines.

\section{Correlated responses to selection}

There were no differences between lines in fecundity and sex ratio measured during the course of selection (Fig. 3). However, there were differences in both traits between selected lines and the unselected control in later generations of the first replicate. Fecundity increased slightly, at least in the first four generations, for all lines in both replicates; however, only that of the unselected control in the first replicate was significant $(\beta=1.900, P=0.039)$. Sex ratio appeared to decline during the course of selection but only that of the disperser line of the first replicate was significant $(\beta=-0.026, P=0.007)$. This decline was probably the result of an increasing number of sons produced as fecundity increased rather than a decrease in the number of daughters (Young et al., 1986). This same phenomenon can be seen in the crosses at the end of the selection (Table 1).

Phenotypic correlations between sex ratio and aerial dispersal behaviour and fecundity were observed in some lines of the first replicate in later generations (Fig. 4). However, there was no change in the two correlations. The correlation between the dispersal behaviour and fecundity in the non-dispersal line in the first replicate declined significantly $(\beta=-0.98, P=0.028)$ but did not change in other lines or between lines.

\section{Crosses between selected lines}

The proportion of mites displaying aerial dispersal behaviour differed significantly between some crosses
(Table 1). The disperser parental line had the highest dispersal rate and the non-disperser parental line the lowest. The difference in the dispersal rate was significant between the two reciprocal crosses in the first replicate but not in the second. The proportions of
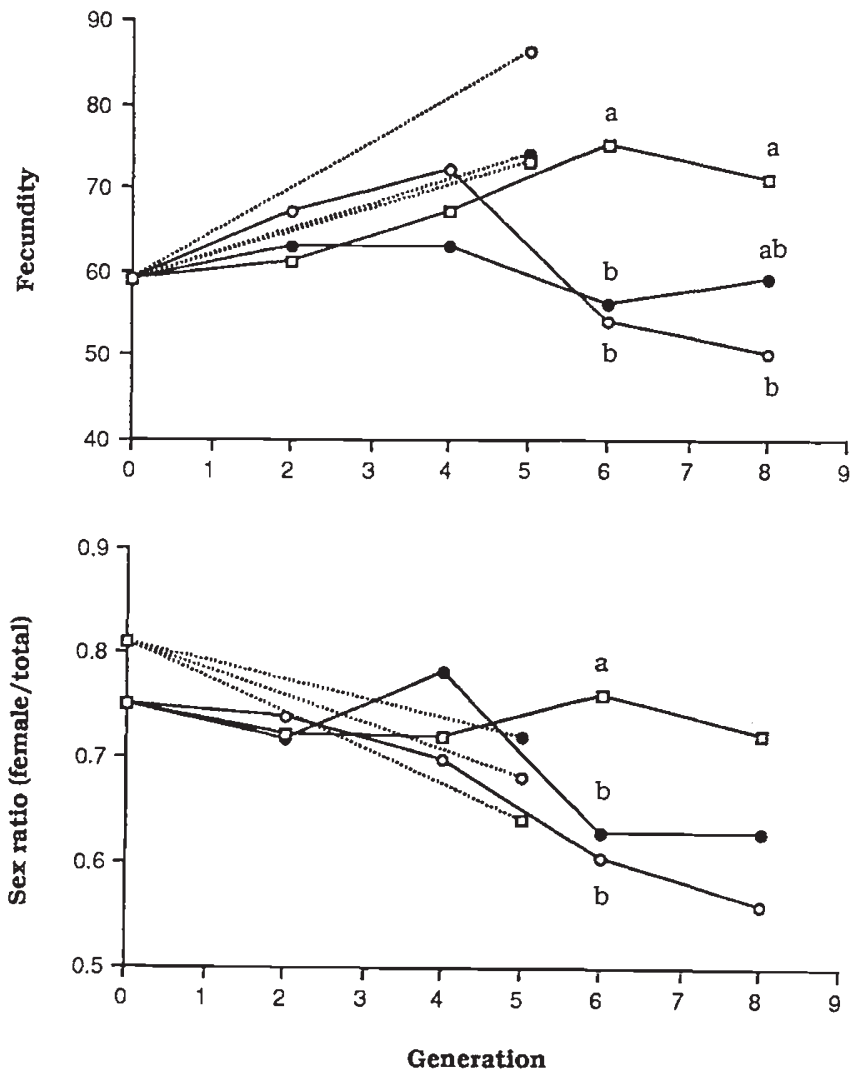

Fig. 3 Fecundity and sex ratio measured during selection in both replicates. Open squares represent the unselected controls. Other symbols as in Fig. 1. Different letters indicate significant difference between lines within a generation $(P<0.05)$.

Table 1 Mean ( \pm s.d.) fecundity, sex ratio, and proportion of mites displaying aerial dispersal behaviour (ADB) in two selected lines and their reciprocal crosses. Estimates of fecundity and sex ratio were based on 10 pairs of parents in each cross. Proportion was based on five tests in the first experiment and six in the second

\begin{tabular}{|c|c|c|c|c|}
\hline \multirow[b]{2}{*}{ Parents } & \multirow[b]{2}{*}{ Fecundity } & \multirow[b]{2}{*}{ Sex ratio } & \multicolumn{2}{|c|}{$\begin{array}{l}\% \text { Mites showing } \\
\text { ADB }\end{array}$} \\
\hline & & & Rep. 1 & Rep. 2 \\
\hline Disperser $\phi \times$ disperser 0 & $65( \pm 15)$ & $0.76( \pm 0.09)$ & $61.8 \mathrm{a}$ & $33.9 \mathrm{a}$ \\
\hline Disperser $Q \times$ non-disperser $\sigma$ & $70( \pm 11)$ & $0.72( \pm 0.13)$ & $29.5 b$ & $14.5 b$ \\
\hline Nondisperser $q \times$ disperser $\varnothing$ & $62( \pm 23)$ & $0.77( \pm 0.12)$ & $22.7 \mathrm{c}$ & $12.4 \mathrm{~b}$ \\
\hline Nondisperser $Q \times$ non-disperser $\sigma^{\prime}$ & $63( \pm 13)$ & $0.76( \pm 0.11)$ & $4.1 \mathrm{~d}$ & $4.0 \mathrm{c}$ \\
\hline
\end{tabular}

Different letters following means within columns indicate significance at $P<0.05$ level. 

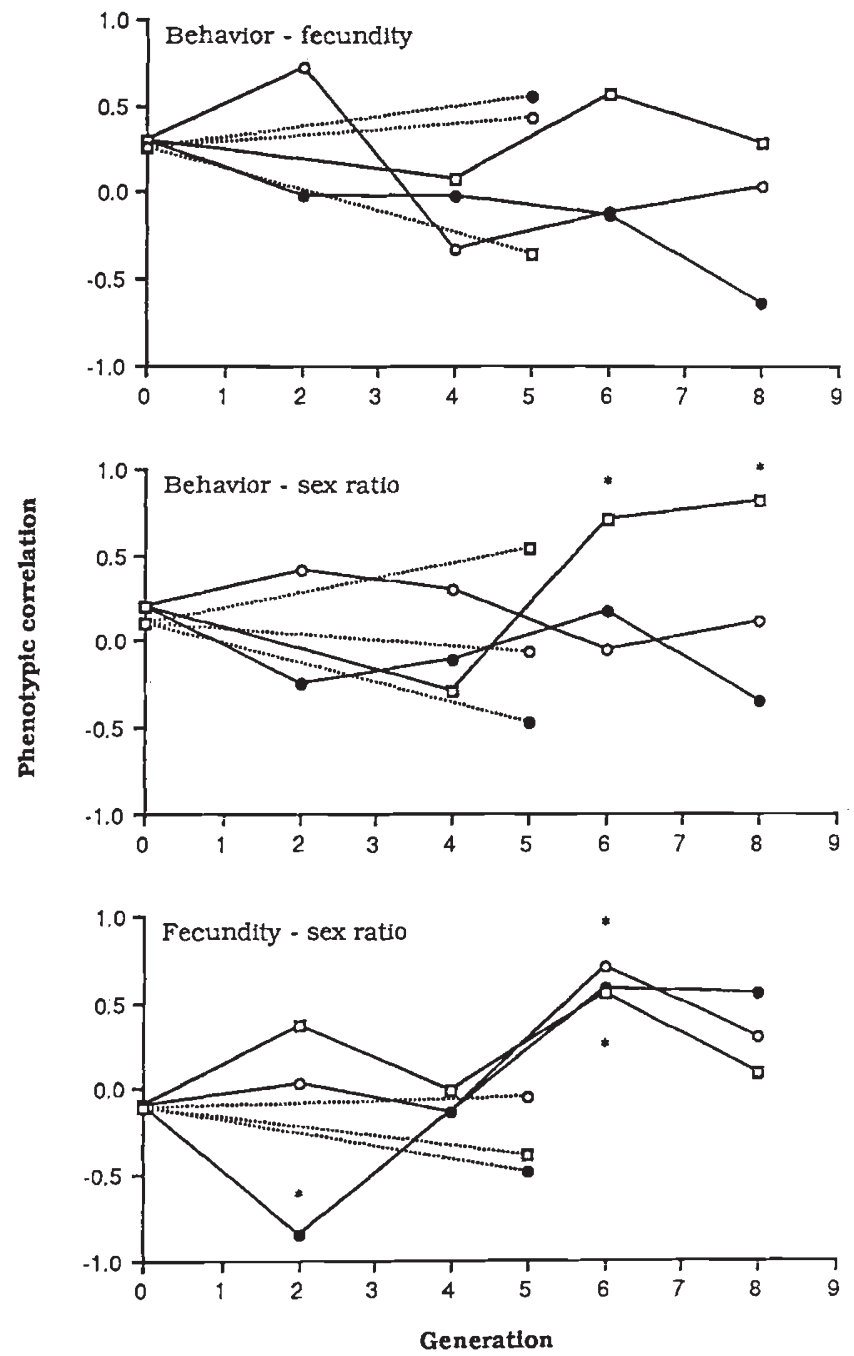

Fig. 4 Phenotypic correlations between aerial dispersal behaviour, fecundity, and sex ratio measured during selection in both replicates. Symbols as in Fig. 3. An asterisk associated with a correlation indicates significance at the $P<0.05$ level.

mites in both reciprocal crosses showing the behaviour were lower than the average of the two parental lines in both selection replicates ( 33 per cent and 19 per cent in the first and second replicates, respectively) although the differences were only marginal $(P=0.063$ and 0.078 for crosses with non-disperser mothers in the first and second replicates, respectively). The difference in the proportion of disperser between the reciprocal crosses was maternally influenced, i.e. the crosses with non-disperser mothers had lower proportions than those with disperser mothers. No difference in fecundity or sex ratio existed between the reciprocal crosses and the two parental lines (Table 1).

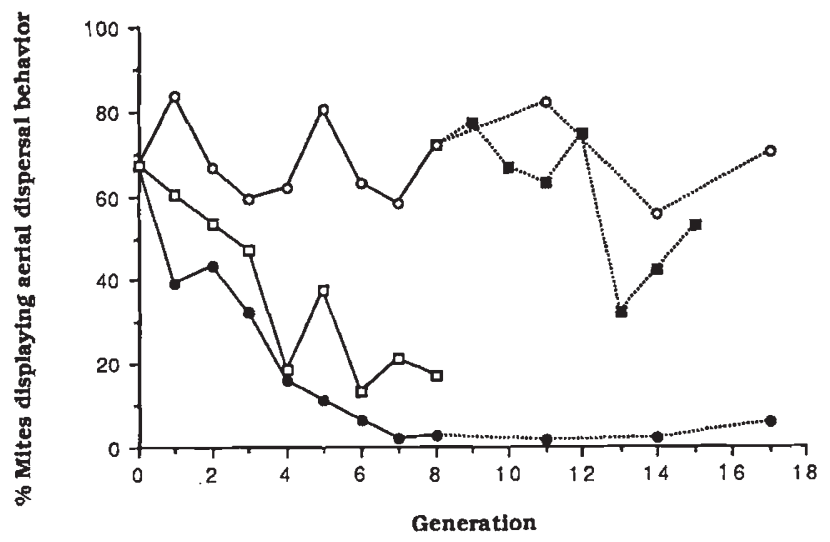

Fig. 5 Mean aerial dispersal responses, measured as the proportion of mites displaying the behaviour, in both selected lines and unselected control in the first replicate. Solid lines represent the generations $(1-8)$ under direct selection on aerial dispersal behaviour, and broken lines the generation (9-17) in which direct selection was discontinued. Open circles represent the disperser line subjected to selection, closed circles the non-disperser line, open squares the unselected control, and closed squares the disperser line with selection relaxed. Open circles connected by broken lines represent the response of the disperser line to a fluctuating environment (i.e. alternating good and poor food quality).

\section{Relaxation of selection}

The proportion of mites displaying dispersal behaviour declined significantly when selection was stopped and mites were maintained on continuously high quality leaves $(\beta=-4.794, P=0.044$, Fig. 5). This was similar to the response of the unselected control during the selection phase of the experiment $(\beta=-6.405$, $P=0.012$ ). However, the proportion of mites displaying the behaviour remained at high levels in the disperser line subjected to continuous selection $(\beta=-0.714, P=0.577)$, and in the line subjected to varying quality food resource even in the absence of direct selection $(\beta=-1.054, P=0.626)$. The dispersal rate also did not change after relaxation of selection on the non-disperser line $(\beta=0.031, P=0.330)$.

\section{Food deprivation and dispersal}

About 99 per cent of the mites in the disperser line, except the ones that were caught in the tanglefoot, displayed the behaviour after being starved for $8 \mathrm{~h}$ whereas only 70 per cent of the non-disperser line showed the behaviour (Fig. 6). A large proportion of mites did not disperse in the non-disperser line after being starved for $8 \mathrm{~h}$ and the frequency distribution indicated a small truncation (about 30 per cent) to the 
right of the distribution curve. On average, 6 per cent of the mites in both selected lines, 7 per cent in the 90min starvation experiment and 9 per cent in the 8-h starvation experiment became trapped in the tanglefoot during tests. There was no difference in mean proportion or latency of aerial dispersal behaviour among the three generations in the disperser line $(H=1.078$, $P=0.583$ and $H=1.344, P=0.511$, respectively). Mean proportion of disperser in the disperser line was the same in both starvation experiments $(U=14$, $P=0.460$ ), whereas mean latency was shorter in the 8-h starvation experiment than in the 90-min starvation experiment $(U=24, P=0.008)$. Both mean proportion and latency of dispersal in the nondisperser line differed in the two starvation experiments $(U=21, P=0.048$ and $U=23, P=0.016$, respectively).

\section{Discussion}

The response to selection on aerial dispersal behaviour which we observed is evidence of genetic influence on
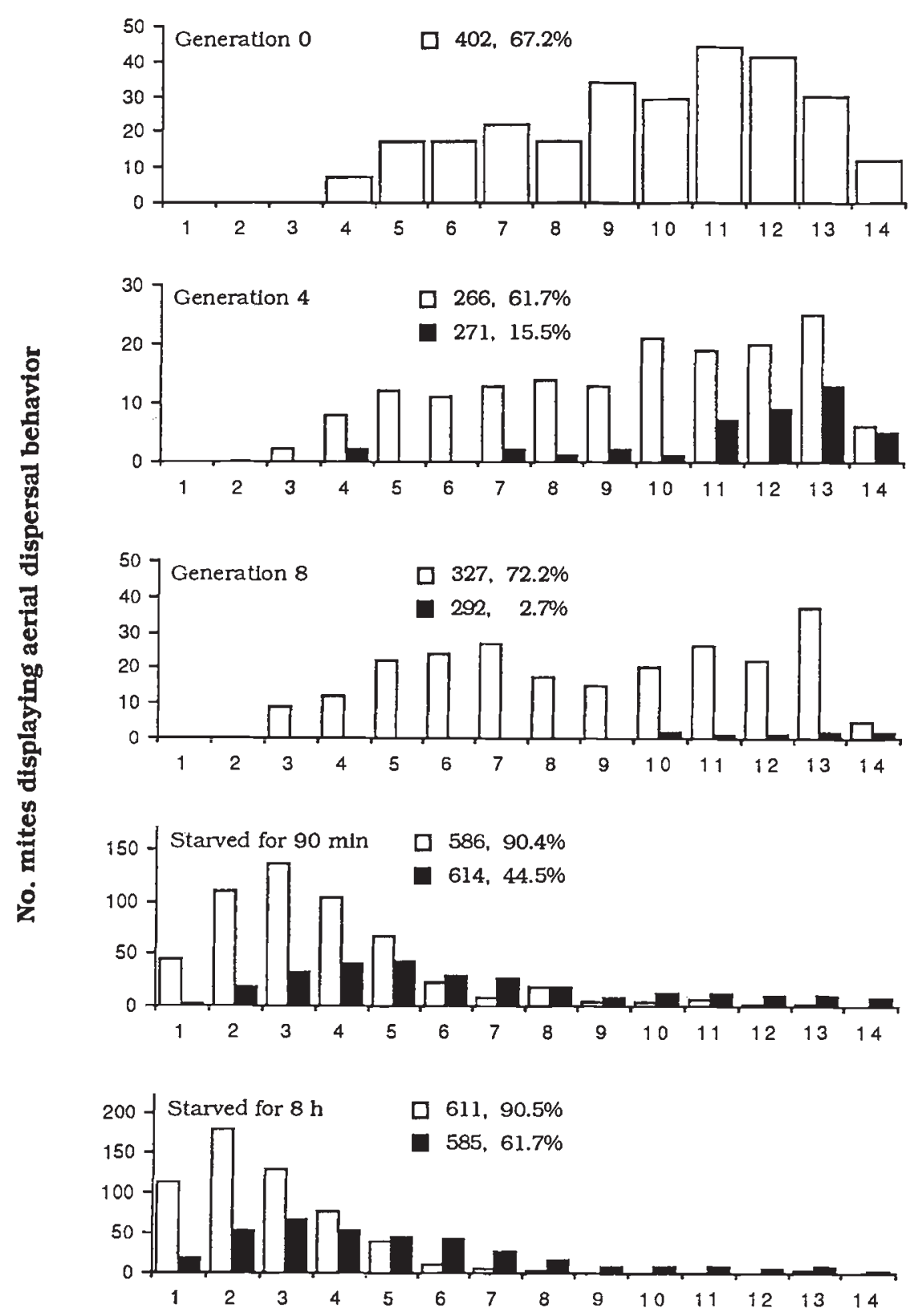

Latency $(\sqrt{\mathrm{min}})$
Fig. 6 Frequency distribution of mites displaying the behaviour in disperser line (open bar) and non-disperser line (closed bar) in generations 0 (base population), 4 and 8 , and in the two starvation experiments. The first number associated with each generation is the number of mites tested and the second is the percentage of mites displaying the behaviour. 
this trait in the twospotted spider mite. There is close agreement between the realized heritability estimated in this study and the heritability obtained in the previous sib-analysis (Li \& Margolies, 1993b). In general, heritability estimates calculated from response to artificial selection are less than 0.5 (Plomin, 1990). This means that most of the variability cannot be attributed to additive genetic variance. Because aerial dispersal behaviour was measured as incidence and analysed as a threshold trait in this study whereas it was measured as latency and analysed as a continuous trait in the previous sib-analysis, agreement between the two studies suggests that the behaviour can be treated as either a continuous trait or a threshold trait without losing any information on its genetic and environmental variation.

In theory, dispersal should be correlated with the ability to persist in a new habitat (Lewontin, 1965; Simberloff, 1981; Safriel \& Ritte, 1983). If life-history traits have evolved to function together to enhance survival and reproduction (Stearns, 1976), then the phenotypic associations predicted in theory should be reflected in genetic correlations between aerial dispersal behaviour and fecundity or sex ratio because of their involvement in colonization and reproduction (Safriel \& Ritte, 1980; Parsons, 1983). Such correlations have been observed in many insect species (e.g. Palmer \& Dingle, 1986; Dingle et al., 1988; Gu \& Danthanarayana, 1992) but neither this study nor the previous sib-analysis (Li \& Margolies, 1993b) provides evidence of such correlations. Neither fecundity nor sex ratio diverged between the two selected lines during the course of selection on aerial dispersal behaviour as would be expected with genetically correlated traits (Lynch, 1980; Falconer, 1981). The consistent lack of phenotypic correlations between aerial dispersal behaviour, fecundity and sex ratio during the course of selection, as well as the similarity in fecundity and sex ratio among crosses made at the end of selection, strongly suggests that aerial dispersal behaviour, fecundity and sex ratio are not genetically correlated in this population of spider mites. We can most easily ascribe the few significant phenotypic correlations we found to environmental influences occurring in a particular generation of a particular line. Although phenotypic correlations may be related to their genetic counterparts (Cheverud, 1988), we cannot always rely on them for evolutionary prediction (Willis et al., 1991).

The crosses between the disperser and non-disperser lines indicated a slight maternal influence on aerial dispersal behaviour. The existence of maternal effects on mite aerial dispersal behaviour was also suggested in the previous sib-analysis. Similar effects were found in the dispersal capacity of the light brown apple moth (Gu \& Danthanarayana, 1992). Maternal inheritance can have a substantial effect on the results of artificial selection and may complicate the response of aerial dispersal behaviour to selection (Falconer, 1965). Maternal inheritance can cause time lags in selection response, can lead to a response after selection ceases and can make the rate and direction of the response vary even under a constant selection intensity (Kirkpatrick \& Lande, 1989). In addition, the selection response may be larger or smaller or even in an opposite direction to that expected.

An unselected control in a selection experiment is important for eliminating common environment effects on selected lines when heritability is estimated (Hill, 1980). It is also important for understanding how the environment affects the trait(s) in question. The rapid decline in the incidence of the dispersal behaviour in the unselected control and its persistence in the disperser line suggest that disperser phenotypes and genotypes can be lost under certain conditions unless specific selection for dispersal occurs. Because mites display the behaviour only in response to food deterioration (Brandenburg \& Kennedy, 1982), mites that do not disperse or are less sensitive to starvation or desiccation may be favoured by selection on high quality food. The results indicated that the proportion of disperser declined rapidly on a high quality food resource or in a stable environment but persisted in an unstable environment in the relaxation study. Therefore, high food quality seems to be a major factor that selects against dispersers. Whatever the mechanisms may be, they should be related to higher fitness of non-dispersers in the local environment. Possible mechanisms are faster developmental rate, earlier reproduction and better mating ability in non-dispersers. However, casual observation during the experiments indicates that dispersers and non-dispersers do not have different developmental rates or reproductive schedules.

In unpredictable environments, populations are expected to exhibit polymorphism for dispersal traits (Southwood, 1977). Genetically-based dispersal polymorphisms are well documented in arthropod populations (Harrison, 1980; Roff, 1986). The persistence of dispersers or non-dispersers when they were reared on varying quality food resources in the relaxation study suggests that different genotypes were maintained under temporally fluctuating environments. Both theoretical (Barton \& Turelli, 1989; Goldstein \& Holsinger, 1992) and empirical (Denno et al., 1991) studies suggest that if different genotypes exist and are favoured by different environments, genetic variation can be maintained by spatially fluctuating environments. Temporally fluctuating environments also may 
maintain genetic variation (Mackay, 1981; Gillespie \& Turelli, 1989) and this may be accomplished by opposing selection on the trait in question.

Aerial dispersal behaviour in the twospotted spider mite, like most continuous traits, is a composite of other characters. Any genetic and environmental variation associated with these underlying characters influences the continuous traits either in responses to selection or in estimating genetic parameters (Riska, 1989; Price \& Schluter, 1991). Starvation and desiccation are the major host-related cues that trigger the behaviour (Smitley \& Kennedy, 1985; Margolies \& Kennedy, 1988). Therefore, variation in mite sensitivity or resistance to these cues contributes to variation of the behaviour. This suggests that the behavioural response is controlled largely by resistance to starvation or desiccation. Because food deterioration in a heavily infested area can only become worse, resistance cannot lead to early dispersal. Many changes in behaviour can be attributed to threshold effects that are closely related to behavioural effects of genetic changes (Ewing \& Manning, 1967). Our results suggest that dispersal behaviour is influenced by its underlying sensitivity or resistance to the environmental cues that trigger it and that selection acts on these traits to lead to changes in the threshold of the behaviour.

Because of the high probability with which those exhibiting the behaviour can be expected to become airborne (Smitley \& Kennedy, 1985; Margolies, 1987), mites exhibiting the aerial dispersal behaviour are considered to be long-distance aerial dispersers. Adaptations for dispersal are often difficult to identify because locomotory behaviour may serve many functions. However, spider mite aerial dispersal behaviour is qualitatively distinct from locomotory behaviours involved in trivial movement (i.e. walking and spinning down) and the resulting spatial displacement is likely to have more profound effects on the survival, and possibly on the reproductive potential, of the dispersing individual. In the twospotted spider mite, dispersers or early dispersers could be completely replaced by non-dispersers in 10-15 generations on high quality food resources as indicated in this study. However, the high developmental and reproductive rates of the mite usually lead to the rapid deterioration of its hosts. Therefore, alternation of good and poor quality food resources must occur before dispersers are completely eliminated. When food resources become depleted, dispersers may be favoured over non-dispersers. Mites in such situations tend to move up to the top of host plants (Brandenburg \& Kennedy, 1982). Less sensitive mites may do so later or not at all. Aerial dispersal behaviour may be maintained in populations of the twospotted spider mite through the combination of rapid destruction of hosts by high mite density and the disturbed nature of crop systems, both of which favour dispersers.

\section{Acknowledgements}

We thank J. Meyer, North Carolina State University, for providing the mite population and B. Black, S. Cox and J. Nechols for helpful comments on an earlier draft. This work was supported by USDA-CRGO Grant No. 88-37234-3499 to D.C.M. Contribution No. 93-40-J from the Kansas Agricultural Experiment Station, Kansas State University, Manhattan, KS.

\section{References}

BARTion, N. H. AND TURELLI, M. 1989. Evolutionary quantitative genetics: how little do we know? Ann. Rev. Genet., 23 , 337-370.

BRANDENBURG, R. L. AND KENNEDY, G. G. 1982. Intercrop relationships and spider mite dispersal in a corn/peanut agro-ecosystem. Entomol. Exp. Appl., 32, 269-276.

CHEVERUD, J. M. 1988. A comparison of genetic and phenotypic correlations. Evolution, 42, 958-968.

CLARK, A. G. 1987. Genetic correlations: the quantitative genetics of evolutionary constraints. In: Loeschcke, V. (ed.), Genetic Constraints on Adaptive Evolution, SpringerVerlag, Berlin, pp. 25-45.

COLlins, R. D. AND MARgolies, D. C. 1991. Possible ecological consequences of heterospecific mating behaviour in two tetranychid mites, Exp. Appl. Acarol., 13, 97-105.

DANIEL, w. W. 1990. Applied Nonparametric Statistics, 2nd edn., PWS-KENT Publishing Company, Boston.

DENNEHY, T. J. AND GRANETT, J. 1984. Spider mite resistance to dicofol in San Joaquin Valley cotton: inter- and intraspecific variability in susceptibility of three species of Tetranychus (Acari: Tetranychidae). J. Econ. Entomol., 77, 1381-1385

DENNO, R. F., RODERICK, G. K., OLMSTEAD, K. L. AND DOBEL, H. G 1991. Density-related migration in planthoppers (Homoptera: Delphacidae): the role of habitat persistence. Am. Nature, 138, 1513-1541.

DINGLE, H. 1984. Behaviour, genes and life histories: complex adaptations in uncertain environments. In: Price, P. W., Slobodchikoff, C. N. and Gaud, W. S. (eds), A New Ecology - Novel Approaches to Interactive Systems, John Wiley \& Sons, New York, pp. 169-194.

DINGLE, H. 1991. Evolutionary genetics of animal migration. Am. Zool., 31, 253-264.

DINGLE, H., BLAU, W. S., BROWN, C. K. AND HEGMANN, J. P. 1982. Population crosses and the genetic structure of milkweed bug life histories. In: Dingle, H. and Hegmann, J. P. (eds), Evolution and Genetics of Life Histories, Springer-Verlag, New York, pp. 209-229.

DINGLE, H., EVANS, K. E. AND PALMER, J. O. 1988. Responses to selection among life-history traits in a non-migratory population of milkweed bugs (Oncopeltus fasciatus). Evolution, 42, 79-92. 
ENDler, J. A. 1986. Natural Selection in the Wild. Princeton University Press, Princeton, NJ.

EWING, A. W. AND MANNING, A. 1967. The evolution and genetics of insect behaviour. Ann. Rev. Entomol., 12, 471-493.

FALCONER, D. S. 1965. Maternal effects and selection response. In: Geerts, S. J. (ed.), Genetics Today, Proceedings of the XI International Congress on Genetics, vol. 3, Pergamon, Oxford, pp. 763-774.

FALCONER, D. S. 1981. Introduction to Quantitative Genetics, 2nd edn., Longman, London, chap. 18.

FRY, J. D. 1989. Evolutionary adaptation to host plants in a laboratory population of the phytophagous mite Tetranychus urticae Koch. Oecologia, 81, 559-565.

GILLESPIE, J. H. AND TURELLI, M. 1989. Genotype-environment interactions and the maintenance of polygenic variation. Genetics, 121, 129-138.

GOLDSTEIN, D. B. AND HOLSINGER, K. E. 1992. Maintenance of polygenic variation in spatially structured populations: roles for local mating and genetic redundancy. Evolution, 46, 412-429.

GOULD, F. 1979. Rapid host range evolution in a population of the phytophagous mite, Tetranychus urticae Koch. Evolution, 33, 791-802.

GU, H. AND DANTHANARAYANA, w. 1992. Quantitative genetic analysis of dispersal in Epiphyas postvittana. II. Genetic covariations between flight capacity and life-history traits. Heredity, 68, 61-69.

HARRISON, R. G. 1980. Dispersal polymorphisms in insects. Ann. Rev. Ecol. Syst., 11, 95-118.

HELLE, w. 1967. Fertilization in the two-spotted spider mite (Tetranychus urticae: Acari). Entomol. Exp. Appl., 10, 103-110.

HELle, w. 1985. Genetics. In: Helle, W. and Sabelis, M. W. (eds), Spider Mites: Their Biology, Natural Enemies and Control, 1A. Elsevier Science Publishers, Amsterdam, pp. 185-192.

HILL, W. G. 1972. Estimation of realized heritabilities from selection experiments. I. Divergent selection. Biometrics, 28, 747-765.

HILL, w. G. 1980. Design of quantitative genetic selection experiments. In: Robertson, A. (ed.), Selection Experiments in Laboratory and Domestic Animals, Commonwealth Agricultural Bureau, Slough, pp. 1-13.

HOULE, D. 1991. Genetic covariance of fitness correlates: what genetic correlations are made of and why it matters. Evolution, 45, 630-648.

HOY, M. A., VAN DE BAAN, H. E., GROOT, J. J. R. AND FIELD, R. P. 1984. Aerial movements of mites in alomons: implications for pest management. Calif. Agric., 38, 21-23.

JEPPSON, L. R., KEIFER, H. H. AND BAKER, E. W. 1975. Mites Injurious to Economic Plants. University of California Press, Berkeley.

KENNEDY, G. G. AND MARGOLIES, D. C. 1985a. Mobile arthropod pests: management in diversified agroecosystems. Bull. Entomol. Soc. aM., 31, 21-27.

KENNEDY, G. G. AND MARGOLIES, D. C. 1985 b. A case history: the twospotted spider mite. In: MacKenzie, D. R., Bonfield, C. S., Kennedy G. G. and Bereger, R. D. with Tartanto,
D. J. (eds), Movement and Dispersal of Agriculturally Important Biotic Agents, Claitor's Publishing Division, Baton Rouge, LA, pp. 443-452.

KIRKPATRICK, M. AND LANDE, R. 1989. The evolution of maternal characters. Evolution, 43, 485-503.

KRAINACKER, D. A. AND CAREY, J. R. 1990. Male demographic constraints to extreme sex ratio in the twospotted spider mite. Oecologia, 82, 417-423.

LANDE, R. 1982. A quantitative genetic theory of life history evolution. Ecology, 63, 607-615.

LEWONTIN, R. C. 1965. Selection for colonizing ability. In: Baker, H. G. and Stebbins, G. L. (eds), The Genetics of Colonizing Species, Academic Press, New York, pp. 77-92.

L1, J. AND MARGOLIES, D. C. 1993a. Effects of mite age and host quality on aerial dispersal behaviour in the twospotted spider mite. Entomol. Exp. Appl. (in press).

LI, J. AND MARGolies, D. C. $1993 \mathrm{~b}$. Quantitative genetics of aerial dispersal behaviour and life history traits in Tetranychus urticae. Heredity, 70, 544-552.

LYNCH, C. B. 1980. Response to divergent selection for nesting behaviour in Mus musculus. Genetics, 96, 757-765.

MACKAY, T. F. C. 1981. Genetic variation in varying environments. Genet. Res., 37, 79-93.

MARGOLIES, D. C. 1987. Conditions eliciting aerial dispersal behaviour in Banks grass mite, Oligonychus pratensis (Acari: Tetranychidae). Environ. Entomol., 16, 928-932.

MARGOLIES, D. C. AND KENNEDY, G. G. 1988. Fenvalerate-induced aerial dispersal by twospotted spider mite. Entomol. Exp. Appl., 46, 233-240.

MITCHELL, R. 1972. The sex ratio of the spider mite Tetranychus urticae. Entomol. Exp. Appl., 15, 299-304.

PAlMeR, J. O. AND Dingle, H. 1986. Direct and correlated responses to selection among life-history traits in milkweed bugs (Oncopeltus fasciatus). Evolution, 40, 767-777.

PARSONS, P. A. 1983. The Evolutionary Biology of Colonizing Species. Cambridge University Press, Cambridge.

PLOMIN, R. 1990. The role of inheritance in behaviour. Science, 248, 183-188.

PRICE, T. AND SCHLUTER, D. 1991. On the low heritability of lifehistory traits. Evolution, 45, 853-861.

RISKA, B. 1989. Composite traits, selection response and evolution. Evolution, 43, 1172-1191.

ROFF, D. A. 1986. The evolution of wing dimorphism in insects. Evolution, 40, 1009-1020.

ROSE, M. R. 1982. Antagonistic pleiotropy, dominance and genetic variation. Heredity, 48, 63-78.

ROSE, M. R. AND CHARLESWORTH, B. 1981a. Genetics of life history in Drosophila melanogaster. I. Sib analysis of adult females. Genetics, 97, 173-186.

ROSE, M. R. AND CHARLESWORTH, B. 1981b. Genetics of life history in Drosophila melanogaster. II. Exploratory selection experiments. Genetics, 97, 187-196.

SAFRIEL, U. N. AND RITTE, U. 1980. Criteria for the identification of potential colonizers. Biol. J. Linn. Soc., 13, 287-297.

SAFRIEL, U. N. AND RITTE, U. 1983. Universal correlates of colonizing ability. In: Swingland, I. R. and Greenwood, P. J. (eds), Ecology of Animal Movement, Clarendon Press, Oxford, pp. 215-239. 
SAS InSTITUTE INC. 1990. SAS/STAT User's Guide. Cary, N.C. SIMBERLOFF, D. 1981. What makes a good island colonist? In Denno, R. F. and Dingle, H. (eds), Insect Life History Patterns: Habitat and Geographic Variation, SpringerVerlag, New York, pp. 195-206.

SMITLEY, D. R. AND KENNEDY, G. G. 1985. Photo-oriented aerialdispersal behaviour of Tetranychus urticae (Acari: Tetranychidae) enhances escape from the leaf surface. Ann. Entomol. Soc. Am., 78, 609-614.

SOKAL, R. R. AND ROHLF, F. J. 1981. Biometry, 2nd edn. W. H. Freeman, San Francisco.

SOUTHWOOD, T. R. E. 1962. Migration of terrestrial arthropods in relation to habitat. Biol. Rev., 37, 171-214.

SOUTHWOOD, T. R. E. 1977. Habitat, the template for ecological strategies. J. Anim. Ecol., 46, 337-366.
STEARNS, S. C. 1976. Life-history tactics: a review of the ideas. Quart. Rev. Biol., 51, 3-49.

SUSKI, $Z$. W. AND NAEGELE, J. A. 1963. Light response in the twospotted spider mite. II. Behaviour of the 'sedentary' and 'dispersal' phases. In: Naegele, J. A. (ed.), Advances in Acarology, vol. 1, Cornell University, Ithaca, pp. 445-453.

TRAVIS, J., EMERSON, S. B. AND BLOUIN, M. 1987. A quantitativegenetic analysis of larval life-history traits in Hyla crucifer. Evolution, 41, 145-156.

WILLIS, J. H., COYNE, J. A. AND KIRKPATRICK, M. 1991. Can one predict the evolution of quantitative characters without genetics? Evolution, 45, 441-444.

YOUNG, S. S. Y., WRENSCH, D. L. AND KONGCHUENSIN, M. 1986. Control of sex ratio by female spider mites. Entomol. Exp. Appl., 40, 53-60. 